\title{
siRNA delivery by a transferrin-associated lipid-based vector: a non-viral strategy to mediate gene silencing
}

\author{
A. L. C. Cardoso ${ }^{1,2}$ \\ S. Simões ${ }^{1,3}$ \\ L. P. de Almeida ${ }^{1,3}$ \\ J. Pelisek ${ }^{4}$ \\ C. Culmsee 4 \\ E. Wagner ${ }^{4}$ \\ M. C. Pedroso de Lima ${ }^{1,2 *}$ \\ ${ }^{1}$ Center for Neuroscience and Cell \\ Biology, University of Coimbra, \\ 3004-517 Coimbra, Portugal
}

${ }^{2}$ Department of Biochemistry, Faculty of Science and Technology, University of Coimbra, Apartado 3126, 3001-401 Coimbra, Portugal

${ }^{3}$ Laboratory of Pharmaceutical Technology, Faculty of Pharmacy, University Pharmacy, University of Coimbra, 3000-295 Coimbra, Portugal

${ }^{4}$ Department of Pharmacy, Ludwig-Maximilians University, Munich, Germany

*Correspondence to:

M. C. Pedroso de Lima, Department of Biochemistry, Faculty of Sciences and Technology, University of Coimbra, Apartado 3126, 3001-401 Coimbra, Portugal. E-mail: mdelima@ci.uc.pt

\section{(बWILEY}

InterScience

Received: 27 July 2006

Revised: 12 December 2006

Accepted: 12 December 2006

\begin{abstract}
Background RNA interference provides a powerful technology for specific gene silencing. Therapeutic applications of small interfering RNA (siRNA) however require efficient vehicles for stable complexation, protection, and extra- and intracellular delivery of these nucleic acids. Here, we evaluated the potential of transferrin (Tf)-associated liposomes for siRNA complexation and gene silencing.
\end{abstract}

Methods Cationic liposomes composed of DOTAP: Cholesterol associated with or without transferrin (Tf) were complexed with siRNA at different lipid/siRNA charge ratios. Complexation and protection of siRNA from enzymatic degradation was assessed with the PicoGreen intercalation assay and gel electrophoresis. Cellular internalization of these siRNA Tf-lipoplexes was detected by confocal microscopy. Luciferase assay, immunoblot and fluorescence-activated cell sorting (FACS) analysis were used to evaluate reporter gene silencing in Huh-7 hepatocarcinoma and U-373 glioma cells. c-Jun knockdown in HT-22 cells was evaluated by quantitative real-time polymerase chain reaction (RT-PCR). Cytotoxicity of the siRNA complexes was assessed by Alamar blue, lactate dehydrogenase and MTT assays.

Results Complexation of siRNA with the cationic liposomes in the presence of $\mathrm{Tf}$ results in the formation of stable particles and prevents serum-mediated degradation. Confocal microscopy showed fast cellular internalization of the Tf-lipoplexes via endocytosis. In the GFP glioma cells Tf-lipoplexes showed enhanced gene silencing at minimum toxicity in comparison to Tf-free lipoplexes. Targeting luciferase in the hepatocarcinoma cell line resulted in more than $70 \%$ reduction of luciferase activity, while in HT-22 cells $50 \%$ knockdown of endogenous c-Jun resulted in a significant protection from glutamate-mediated toxicity.

Conclusions Cationic liposomes associated with Tf form stable siRNA lipoplexes with reduced toxicity and enhanced specific gene knockdown activity compared to conventional lipoplexes. Thus, such formulations may constitute efficient delivery systems for therapeutic siRNA applications. Copyright $\odot 2007$ John Wiley \& Sons, Ltd.

Keywords cationic liposomes; transferrin; siRNA delivery; serum protection; gene silencing; c-Jun; glutamate toxicity 


\section{Introduction}

RNA interference (RNAi) is an important biological process and a useful tool to modulate gene expression with implications in several fields, such as functional genomics, drug validation, and even transgenic design [1-4]. The discovery of RNAi has generated enthusiasm within the scientific community and its application for therapeutic purposes has been tested recently in several disease models that include viral infection [5-7], cancer [8-11], acute hepatitis $[12,13]$, and dominantly inherited genetic disorders [14-16].

Sequence-specific post-transcriptional gene silencing is mediated by small interfering RNAs (siRNAs), about 21-23 nucleotides long, that originate from long doublestranded (ds)RNAs of endogenous or exogenous origin, after cleavage by a type III ribonuclease named DICER [17]. siRNA fragments are incorporated into a nuclease complex called RISC (RNA-induced silencing complex) where the RNA is unwound and one of the strands is released [18]. The active RISC complex is responsible for targeting and cleaving mRNA that is complementary to the siRNA [19].

RNAi holds a pronounced therapeutic potential, since application of siRNA may allow highly specific targeting of selected proteins without the common adverse effects of less specific drug-based therapies or the dangers of viral gene therapy. In addition, double-stranded siRNA is more stable and allows effective knockdown at lower concentrations and for longer time periods compared to single-stranded oligonucleotides used in antisense technology [20]. In addition, RNAi acts primarily in the cytoplasm, which is easier to access than the nucleus, thus avoiding one of the major obstacles of plasmid DNA delivery - the nuclear barrier. Nevertheless, the development of RNAi-based therapeutics faces some of the same challenges which have delayed the successful application of conventional gene therapy, including the design of suitable vectors able to cross the gap between cell culture and animal models, thus allowing an efficient and stable siRNA delivery in vivo. Currently, chemically synthesized siRNA is most effectively introduced into cells using electroporation [21,22] or commercially available lipid reagents, but these methods are poorly suited for in vivo delivery, due to their lack of efficiency or significant non-specific gene silencing [23]. So far, the vast majority of in vivo studies employing RNA interference technology have used high doses of non-modified naked siRNAs, usually delivered through hydrodynamic injection [24]. Although promising, this method has raised several safety concerns associated with the high siRNA dose necessary to achieve efficient silencing. Recent studies suggest that high shRNA concentrations can overwhelm the endogenous machinery responsible for siRNA and miRNA mediated silencing, and then induce considerable cytotoxic effects [25]. Although no such concerns have been reported regarding siRNAs, low concentrations of both siRNA and delivery agents should be preferred, in order to avoid activation of the mammalian immune system [26-28]. In this context, cationic liposome carriers can help to significantly reduce necessary siRNA doses for efficient gene silencing by enhancing siRNA stability in the serum and improving cellular uptake. These lipid-based formulations also present a high degree of versatility that allows modifications which result in a significant increase of their targeting specificity and transfection capacity [29-32]. In this regard, DOTAP: Cholesterol/DNA complexes have been widely explored by us for both in vitro $[30,33]$ and in vivo [29] gene therapy applications, mainly due to their capacity to mediate transfection in the presence of serum. The resistance to inhibition by serum exhibited by this formulation is related to the presence of cholesterol, a helper lipid, that can potentially reduce undesired interactions of lipoplexes with serum proteins, hence increasing their stability in biological systems [34-37].

Transfection activity can be enhanced by the association of targeting ligands such as antibodies, peptides or proteins to the complexes, which exploit the diversity of receptors existent at the surface of each cell type $[31,32,38]$. One useful cell-binding ligand is transferrin (Tf), an iron-transporting protein, which interacts with receptors ubiquitously expressed in various tissues [39]. Targeting Tf receptors has been successfully applied for DNA delivery by using antibodies against these receptors $[40,41]$, by linking the ligand to pegylated liposomes [42], or by associating the protein to cationic liposomes through electrostatic interactions $[32,38,43]$. In this regard, we and others have recently demonstrated that association of $\mathrm{Tf}$ to lipoplexes significantly enhances transfection efficiency by promoting lipoplex internalization in a large variety of cells, including dividing and non-dividing cells, e.g. neurons [29,30,32,38,43-45]. In addition, we have reported that $\mathrm{Tf}$ can trigger cytoplasmic delivery of the carried nucleic acids through destabilization of the endosomal membrane under acidic conditions, thus further improving the transfection process [32,33].

However, despite the widespread use of proteinassociated cationic liposomes, there are still very few reports concerning their application for siRNA delivery. The present study aims to show that Tf-lipolexes, well known for their ability to deliver DNA in vitro and in vivo, can also be optimized for siRNA delivery, resulting both in efficient levels of intracellular siRNA and promising gene silencing effects. We applied the optimized Tflipoplexes to transfer siRNA targeting stably expressed reporter genes such as the green fluorescent protein (GFP) and firefly luciferase in U-373 glioblastoma and Huh-7 hepatocarcinoma cells, as well as siRNA targeting the endogenous transcription factor c-Jun in HT-22 immortalized mouse hippocampal neurons. Since c-Jun plays a key role in neuronal cell death in a wide variety of injury models relevant to neurodegenerative diseases [46], we finally addressed the therapeutic potential of c-Jun siRNA-Tf-lipoplexes against glutamate toxicity in the HT-22 neuronal cell line. 


\section{Materials and methods}

\section{Materials}

The cationic lipid 1,2 dioleoyl-3(trimethylammonium) propane (DOTAP) and cholesterol (Chol) were purchased from Avanti Polar Lipids (Alabaster, AL, USA). Iron-saturated human transferrin (Tf) was obtained from Sigma (St. Louis, MO, USA). The anti-GFP siRNA (5'-GCAAGCUGACCCUGAAGUUCAU-3') and Cy3labeled non-specific siRNA sequence were purchased from Ambion (Austin, TX, USA). The anti-luciferase siRNA (luciferase Gl2 duplex) and the non-silencing siRNA used as control were obtained from Dharmacon (Lafayette, CO, USA). The anti-c-Jun siRNA (5'-AGTCATGAACCACGTTAAC-3') was obtained from Thermo Byoproducts. All the other chemicals were obtained from Sigma unless stated otherwise.

\section{Liposome and complex preparation}

Cationic liposomes composed of DOTAP : Chol (1: 1 molar ratio) were prepared as previously described by Campbell [47]. Briefly, a mixture of the appropriate amounts of lipids, from stock solutions in chloroform, was dried under nitrogen in order to obtain a thin lipid film. The film was dissolved in $100 \mu \mathrm{l}$ of ultrapure ethanol and the resulting ethanol solution was injected in $900 \mu \mathrm{l}$ of HBS buffer (Hepes-buffered saline solution, $20 \mathrm{nM}$ Hepes, $100 \mathrm{mM}$ $\mathrm{NaCl}, \mathrm{pH}$ 7.4) continuously maintained under vortex, employing a $250 \mu \mathrm{l}$ Hamilton syringe. The resulting MLV (multilamellar vesicles) were sonicated briefly to obtain SUV (small unilamellar vesicles), diluted with HBS to a final lipid concentration of $1 \mathrm{mg} / \mathrm{ml}$, and stored at $4{ }^{\circ} \mathrm{C}$ until use.

Cationic liposome/siRNA complexes were prepared by sequentially mixing $100 \mu \mathrm{l}$ of HBS buffer with liposomes (whose volume was dependent on the desired $(+/-)$ charge ratio) and with $10 \mu \mathrm{l}$ of a $5 \mathrm{pmol} / \mu \mathrm{l}$ siRNA solution. The mixture was further incubated for $15 \mathrm{~min}$ at room temperature.

Tf-lipoplexes were prepared by pre-incubating cationic liposomes with iron-saturated human $\mathrm{Tf}(32 \mu \mathrm{g} / \mu \mathrm{g}$ of siRNA) for $15 \mathrm{~min}$, before mixing $10 \mu \mathrm{l}$ of siRNA solution and further incubating the mixture for $15 \mathrm{~min}$, at room temperature. All formulations were used immediately after preparation.

\section{PicoGreen intercalation assay}

The accessibility of the fluorescent intercalating probe PicoGreen (Molecular Probes, Carlsbad, CA, USA) to the siRNA associated with the cationic liposomes was evaluated at $37^{\circ} \mathrm{C}$, for $2 \mathrm{~min}$, in a SPEX Fluorolog spectrometer (SPEX Industries, Edison, NJ, USA). Briefly, PicoGreen fluorescence was detected at excitation and emission wavelengths of 480 and $520 \mathrm{~nm}$, respectively.
The sample chamber was equipped with a stirring device and the temperature was controlled with a feedbackregulated circulating water bath. The fluorescence scale was calibrated such that the initial fluorescence of PicoGreen (1 $\mathrm{ml}$ of $1: 200$ solution added to the cuvette containing $1 \mathrm{ml}$ of HBS) was set as residual fluorescence. The value of fluorescence obtained upon addition of $400 \mathrm{ng}$ of siRNA (control) minus residual fluorescence was set as $100 \%$. Plain complexes or Tf-lipolexes, containing $400 \mathrm{ng}$ of siRNA in $1 \mathrm{ml}$ HBS buffer, were added to the cuvette containing $1 \mathrm{ml}$ of PicoGreen solution. The amount of siRNA available to interact with the probe was calculated by subtracting the values of residual fluorescence (PicoGreen without siRNA) from those obtained for each measurement, and expressed as a percentage of the control that contained naked siRNA only, according to the following formula: \% free $\operatorname{siRNA}=\left(\right.$ PicoGreen fluorescence complexes $_{\text {PicoGreen }}$ fluorescence naked siRNA $\times 100$. The proper controls were performed in order to exclude a possible non-specific decrease in PicoGreen fluorescence due to the presence of lipid or protein.

\section{Protection from RNase and serum-mediated degradation}

Resistance of complexes to RNase and serum-mediated degradation were determined by electrophoresis and ethidium bromide staining. Complexes containing $500 \mathrm{ng}$ of siRNA were submitted to $30 \mathrm{~min}$ incubation at $37^{\circ} \mathrm{C}$, in the presence of $0.1 \mathrm{U} / \mu \mathrm{l} \mathrm{RNaseV} 1$ (Ambion), or to different incubation periods in $50 \%$ mouse serum (Jackson Immuno Research Laboratories Inc., West Grove, PA, USA) in HBS buffer. Parallel experiments were performed by incubating the samples under the same experimental conditions in the absence of serum or RNase V1 or in the presence of heat-inactivated mouse serum. After siRNA extraction using Tri-Reagent ${ }^{\mathrm{TM}}$ (Sigma) and precipitation overnight at $-20^{\circ} \mathrm{C}$, the resuspended samples were analyzed in a $15 \%$ polyacrylamide gel for $2 \mathrm{~h}$, applying a voltage of $110 \mathrm{~V}$. The gel was stained for $5 \mathrm{~min}$ in ethidium bromide and the intensity of the siRNA bands analyzed using the Versa Doc imaging system (Bio-Rad, Hercules, CA, USA).

\section{Measurement of particle size and zeta-potential}

Particle size of Tf-lipolexes was measured by laserlight scattering using a Malvern Zetasizer 3000HS (Malvern Instruments, Worcestershire, UK). The Tflipolexes containing $10 \mu \mathrm{g}$ siRNA were prepared at $3 / 2$ or $2 / 1$ lipid/siRNA $(+/-)$ charge ratios and diluted to a final volume of $2 \mathrm{ml}$ with HBS buffer containing $10 \%$ serum. For evaluation of the zeta-potential the Tflipolexes were further diluted in $10 \mathrm{mM} \mathrm{NaCl}$ to give a final siRNA concentration of $2 \mu \mathrm{g} / \mu \mathrm{l}$. Zeta-potential and 
particle size of the formulations were determined in at least two independent experiments, each with five or ten independent measurements, respectively.

\section{Generation of U-373/eGFP and Huh-7/eGFPLuc cell lines}

For the generation of stably transfected cells, the vectors pEGFP or pEGFPLuc (Clontech, Palo Alto, USA) were linearized using the restriction enzyme Dra III, and U-373 or Huh-7 cells were transfected with the respective linearized vectors using linear polyethylenimine $22 \mathrm{kDa}$ (PEI22) polyplexes generated in HEPES-buffered saline + HEPES-buffered glucose 1:1 (HBS1/2: $75 \mathrm{mM} \mathrm{NaCl}$, $2.5 \%$ glucose, $20 \mathrm{mM}$ HEPES, $\mathrm{pH}$ 7.2) with a PEI nitrogen to DNA phosphate $(\mathrm{N} / \mathrm{P})$ ratio of $6 / 1$. Cells were incubated in fresh medium for $72 \mathrm{~h}$ and then selected with 60

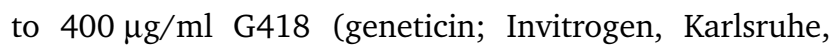
Germany). After several days, surviving cells were seeded at low densities into six-well plates in order to generate separate colonies. Single cell clones were then isolated and expanded. The generated clones were analyzed for the percentage of GFP-positive (eGFPLuc stably transfected) cells. Clones with the highest amount of GFP-positive cells were then further selectively grown under the above described selective conditions and this procedure was repeated until all cells were positive for GFP. These stably transfected U-373/eGFP or Huh7/eGFPLuc cells were then used for siRNA delivery experiments.

\section{Cell culture and siRNA delivery}

U-373 cells (glioblastoma-derived cell line) stably expressing GFP, Huh-7 cells (hepatocarcinoma-derived cell line) stably expressing a GFP-Luc fusion protein, and HT-22 cells (immortalized mouse hippocampal neurons [48]) were incubated at $37^{\circ} \mathrm{C}$ in an humidified atmosphere containing $5 \% \mathrm{CO}_{2}$. Both U-373 and HT-22 cell lines were maintained in DMEM (Dulbecco's modified Eagles's medium) (Sigma), while Huh-7 cells were maintained in DMEM/Ham's F12 (GIBCO, Paisley, Scotland). Both culture media were supplemented with $10 \%$ heat-inactivated fetal bovine serum (FBS) (GIBCO), $100 \mu \mathrm{g} / \mathrm{ml}$ streptomycin and $1 \mathrm{U} / \mathrm{ml}$ penicillin. In the case of the $\mathrm{U}-373$ cell line, DMEM was also supplemented with $24 \mu \mathrm{l} / \mathrm{ml}$ of the selection antibiotic Geneticin ${ }^{\circledR}$ (GIBCO) for a final concentration of $50 \mathrm{mg} / \mathrm{ml}$.

Twenty-four hours before any experiment, U-373, Huh-7 and HT-22 cells were plated at a density of 25000 cells $/ \mathrm{cm}^{2}$. Immediately before addition of the complexes, the cells were washed and the medium was replaced with fresh medium, and $100 \mu \mathrm{l}$ of plain or Tf-lipolexes prepared at different lipid/siRNA $(+/-)$ charge ratios were added to the cells to a final siRNA concentration of $1 \mu \mathrm{M}$. As a positive control for siRNA delivery, Lipofectamine 2000 (Invitrogen, Carlsbad, CA,
USA) diluted in OPTIMEM (GIBCO) was used according to the manufacturer's instructions. In addition, a nonsilencing siRNA sequence was used in parallel with the anti-GFP, anti-luciferase or anti-c-Jun sequences, in order to ensure that the decrease in protein levels was attributable to the selected siRNA and not to the vector per se. After $4 \mathrm{~h}$ of incubation the medium was replaced and the cells were further incubated for different periods of time, before evaluation of siRNA transfection.

\section{Epifluorescence and confocal microscopy studies}

Following siRNA transfection, the number of GFP-positive cells was determined by epifluorescence microscopy using a Axiovert 200 microscope (Zeiss, Thornwood, NY, USA), equipped with the $20 \times$ objective. Briefly, $48 \mathrm{~h}$ after complex delivery, U-373 cells were washed with phosphate-buffered saline (PBS), fixed with 4\% paraformaldehyde for $15 \mathrm{~min}$ at room temperature, stained with the fluorescent DNA-binding dye Hoechst $33342(1 \mu \mathrm{g} / \mathrm{ml})$, rinsed again with PBS and mounted in Vecta Shield mounting medium (Vecta Laboratories Inc., Burlingame, CA, USA) for subsequent analysis. For each experimental condition, the number of blue nuclei and green cells was counted in nine separate coverslips (an average of 300 cells per coverslip) and results were expressed as the percentage of GFP-positive cells of total cell number per field. In addition, for analysis of cellular uptake of siRNA and Tf-lipoplexes, Huh-7 cells were incubated for $4 \mathrm{~h}$ with naked or complex-associated Cy3-labeled siRNAs. Following incubation, the cells were washed and mounted in PBS and immediately visualized by confocal microscopy. All observations were made using a Axiovert confocal scanning microscope (Zeiss, Jena, Germany), under the $60 \times$ oil immersion objective.

\section{Fluorescence-activated cell sorting (FACS) analysis}

Flow cytometric data were obtained in a $\operatorname{Cyan}^{\mathrm{TM}}$ MLE flow cytometer (DaKoCytomation, Copenhagen, Denmark). Seventy-two hours after siRNA delivery, U-373 cells were washed with PBS and treated with trypsin (10 min, $37^{\circ} \mathrm{C}$ ) to allow detachment from the wells. After trypsin inactivation with medium, cells were centrifuged at $1000 \mathrm{rpm}$ and the supernatant was removed. The remaining pellet was resuspended in $600 \mu \mathrm{l}$ PBS with $4 \%$ paraformaldehyde and placed on ice until further analysis. To discriminate between viable and dead cells and to exclude doublets, cells were appropriately gated by forward/size scatter and pulse width and $1 \times 10^{4}$ gated events were collected per sample. The FITC bandpass filter was used in emission detection. Tf-complex-mediated GFP silencing was expressed as percentage of GFP mean fluorescence in controls. 


\section{Western blot analysis}

Forty-eight hours after siRNA delivery, protein extracts were obtained from U-373 cells using a lysis buffer containing protease inhibitors (Sigma). Protein content was determined using the Bio-Rad protein quantification kit and $20 \mu \mathrm{g}$ of total protein were ressuspended in loading buffer ( $20 \%$ glycerol, $10 \%$ sodium dodecyl sulfate (SDS), $0.1 \%$ bromophenol blue), incubated for $2 \mathrm{~min}$ at $95^{\circ} \mathrm{C}$, and loaded onto a $10 \%$ polyacrylamide gel. After electrophoresis the proteins were blotted onto a PVDF membrane according to standard protocols. After blocking in $5 \%$ non-fat milk, the membrane was incubated with an anti-GFP antibody $(1: 1000)$ (Roche, Indianapolis, IN, USA) overnight at $4{ }^{\circ} \mathrm{C}$, and with the appropriate secondary antibody $(1: 20000)$ (Amersham, Uppsala, Sweden) for $2 \mathrm{~h}$ at room temperature. Equal protein loading was shown by reprobing the membrane with an anti- $\alpha$-tubulin antibody $(1: 10000)$ (Sigma) and with the same secondary antibody. After this incubation period, the blots were washed several times with saline buffer (TBS/T: $25 \mathrm{mM}$ Tris-HCl, $150 \mathrm{mM} \mathrm{NaCl,} \mathrm{0.1 \%} \mathrm{Tween}$ and $5 \mathrm{mg} / \mathrm{ml}$ non-fat powder milk) and incubated with ECF (alkaline phosphatase substrate; $20 \mu \mathrm{l}$ of ECF $/ \mathrm{cm}^{2}$ of membrane) for $5 \mathrm{~min}$ at room temperature and then submitted to fluorescence detection at $570 \mathrm{~nm}$ using a Storm-860 (Molecular Dynamics, CA, USA). For each membrane, the analysis of band intensity was performed using the Quantity One software (Bio-Rad).

\section{Luciferase activity evaluation}

Luciferase gene silencing, mediated by Tf-lipoplexes, was measured in protein extracts from Huh-7 cells using a luciferase detection kit, according to the protocol provided by the manufacturer (Promega, Madison, WI, USA). Briefly, $48 \mathrm{~h}$ after delivery of Tf-lipolexes, cells were lysed with luciferase lysis buffer (Promega) for $15 \mathrm{~min}$ at room temperature. Then $20 \mu \mathrm{l}$ of protein extract were removed from each well and added to $100 \mu \mathrm{l}$ of luciferase assay buffer, containing luciferin. Luciferase activity, measured as relative light units (RLU), was immediately evaluated in a SpectraFluorPlus luminometer (Tecan, Männedorf, Switzerland) and the data were expressed as percentage of control (untreated cells).

\section{Cell viability assays}

Following siRNA transfection of U-373 cells under the different experimental conditions, cell viability was quantified by a modified Alamar blue assay [49]. The assay measures the redox capacity of cells due to the production of metabolites as a result of cell growth, and allows the determination of viability over the culture period without detachment of adherent cells. Briefly, $1 \mathrm{ml}$ of $10 \%(\mathrm{v} / \mathrm{v})$ Alamar blue dye in complete DMEM medium was added to each well 24 or $48 \mathrm{~h}$ following the initial incubation period with Tf-lipoplexes $(4 \mathrm{~h})$. After $2 \mathrm{~h}$ of incubation at $37^{\circ} \mathrm{C}, 150 \mu \mathrm{l}$ of supernatant were collected from each well and transferred to 96-well plates. The absorbance at 570 and $600 \mathrm{~nm}$ was measured in a microplate reader (SLT Lab instruments Spectra). Cell viability was calculated as percentage of control cells using the formula: $\left(A_{570}-A_{600}\right)$ of treated cells $\times 100 /\left(A_{570}-A_{600}\right)$ of control cells.

Alternatively, plasma membrane integrity after siRNA transfection was evaluated using the lactate dehydrogenase (LDH) assay. This assay monitors the conversion of NADH into NAD ${ }^{+}$by LDH at $340 \mathrm{~nm}$. The LDH released into the extracellular medium by damaged cells was expressed as a percentage of the total LDH activity in the cells (\% LDH released = extracellular $\mathrm{LDH} /$ (extracellular $\mathrm{LDH}+$ intracellular LDH)).

Viability of HT-22 cells, following delivery of therapeutic (anti-c-Jun) siRNAs and glutamate-induced toxicity, was determined in 96-well plates by 3(4,5dimethylthiazol-2-y1)-2,5-diphenyltetrazolium bromide (MTT) reduction. Forty-eight hours after Tf-complex delivery, glutamate was added to a final concentration of $2 \mathrm{mM}$. After $18 \mathrm{~h}$ of glutamate exposure, the cells were washed with fresh growth medium and further incubated with MTT $(0.25 \mathrm{mg} / \mathrm{ml})$ for $2 \mathrm{~h}$ at $37^{\circ} \mathrm{C}$. The reaction was terminated by adding dimethyl sulfoxide solution and the absorbance was determined at 590 and $630 \mathrm{~nm}$ in an ELISA microplate reader (Spectra FluorPlus; Tecan, Durham, NC, USA). Cell viability was calculated as percentage of control cells using the formula: $\left(A_{590}-A_{630}\right)$ of treated cells $\times 100 /\left(A_{590}-A_{630}\right)$ of control cells.

\section{Extraction of RNA and cDNA synthesis}

For each condition, total RNA was extracted from $1 \times 10^{6}$ HT-22 cells using the RNeasy Mini kit (Quiagen, Hilden, Germany), according to the manufacturer's recommendations for cultured cells. Briefly, after cell lysis, the total RNA was adsorbed to a silica matrix, washed with the recommended buffers, and eluted with $40 \mu \mathrm{l}$ of RNase-free water by centrifugation. After RNA quantification, cDNA conversion was performed using the Superscript III First Strand synthesis kit (Invitrogen, Karlsruhe, Germany), according to the manufacturer's instructions. For each sample, cDNA was produced from $0.5 \mu \mathrm{g}$ of total RNA in an iQ5 thermocycler (Bio-Rad), by applying the following protocol: $10 \mathrm{~min}$ at $25^{\circ} \mathrm{C}$, $30 \mathrm{~min}$ at $55^{\circ} \mathrm{C}$ and $5 \mathrm{~min}$ at $85^{\circ} \mathrm{C}$. After cDNA synthesis, a $30 \mathrm{~min}$ incubation period with RNase $\mathrm{H}$ at $37^{\circ} \mathrm{C}$ was performed in order to remove any remaining RNA contamination. Finally, the cDNA was diluted $1: 3$ with RNase-free water prior to quantification by quantitative real-time polymerase chain reaction (QRT-PCR).

\section{QRT-PCR}

QRT-PCR was performed in an iQ5 thermocycler (BioRad) using 96-well microtiter plates and the iQ SYBR 
Green Supermix kit (Bio-Rad). The primers for the target gene (c-Jun) and the two tested house-keeping genes (GADPH and HPRT) were pre-designed by Quiagen (QuantiTect Primer, Quiagen). A master mix was prepared for each primer set, containing a fixed volume of SYBR Green Supermix and the appropriate amount of each primer, to yield a final concentration of $150 \mathrm{nM}$. For each reaction, $20 \mu \mathrm{l}$ of master mix were added to $5 \mu \mathrm{l}$ of template cDNA. All reactions were performed in duplicate (two cDNA reactions per RNA sample) at a final volume of $25 \mu \mathrm{l}$ per well, using the iQ5 Optical System software (Bio-Rad). The reaction conditions consisted of: enzyme activation and well-factor determination at $95^{\circ} \mathrm{C}$ for $1 \mathrm{~min}$ and $30 \mathrm{~s}$ followed by 40 cycles at $95^{\circ} \mathrm{C}$ for $10 \mathrm{~s}$ (denaturation), $30 \mathrm{~s}$ at $55^{\circ} \mathrm{C}$ (annealing) and $30 \mathrm{~s}$ at $72{ }^{\circ} \mathrm{C}$ (elongation). The melting curve protocol started immediately after amplification and consisted of $1 \mathrm{~min}$ heating at $55^{\circ} \mathrm{C}$ followed by 80 steps of $10 \mathrm{~s}$, with a $0.5^{\circ} \mathrm{C}$ increase in temperature at each step. Threshold values for threshold cycle determination $\left(C_{t}\right)$ were generated automatically by the iQ5 Optical System software. The percentage of c-Jun knockdown was determined by the $\Delta \Delta \mathrm{C}_{\mathrm{t}}$ method, using HPRT as reference gene, according to the formulas: $\Delta \mathrm{C}_{\mathrm{t}(\mathrm{c}-\text { Jun siRNA })}=\mathrm{C}_{\mathrm{t}(\mathrm{c}-\text { Jun gene })}-$ $\mathrm{C}_{\mathrm{t}(\text { HPRT gene })} ; \Delta \mathrm{C}_{\mathrm{t} \text { (Mut siRNA })}=\mathrm{C}_{\mathrm{t} \text { (c-Jun gene })}-\mathrm{C}_{\mathrm{t} \text { (HPRT gene })}$; $\Delta \Delta \mathrm{C}_{\mathrm{t}}=\Delta \mathrm{C}_{\mathrm{t}(\mathrm{c}-\text { Jun siRNA })}-\Delta \mathrm{C}_{\mathrm{t}(\text { Mut siRNA })} ; \%$ knockdown $=100 \%-\left(2^{-\Delta \Delta \mathrm{Ct}} \times 100\right)$. The $\Delta \Delta \mathrm{C}_{\mathrm{t}}$ value indicates the changes in RNA transcription caused by treatment with anti-c-Jun siRNAs, normalized to RNA transcription changes in cells treated with Mut siRNAs. When positive, the $\Delta \Delta \mathrm{C}_{\mathrm{t}}$ value indicates downregulation of the target mRNA.

\section{Statistical analysis}

All data are presented as means \pm standard deviation (SD) of at least three independent experiments, each performed at least in triplicate. One way analysis of variance (ANOVA) combined with the Tukey posthoc test was used for multiple comparisons in cell culture experiments. Statistical differences are presented at probability levels of $p<0.05, p<0.01$ and $p<0.001$.

\section{Results}

\section{Characterization of cationic liposome/siRNA lipoplexes}

The PicoGreen intercalation assay was applied for monitoring complex formation of siRNA and cationic liposomes, composed of DOTAP and cholesterol at increasing lipid/siRNA charge ratios and in the presence or absence of transferring (Tf).

As shown in Figure 1, a significant quenching of the PicoGreen fluorescence was achieved at the lipid/siRNA charge ratio of $3 / 2(+/-)$, this being almost complete for higher charge ratios, which indicates a very high degree of siRNA complexation (approximately 90\%) by cationic liposomes, in the absence or presence of $\mathrm{Tf}$. These results demonstrate that complexes can be formed through electrostatic interactions between siRNA and cationic liposomes, although an excess of cationic lipid is required to ensure efficient nucleic acid protection. It is interesting to note that association of $\mathrm{Tf}$ to the cationic liposomes does not result in a significant increase of PicoGreen fluorescence over that observed for plain lipoplexes, which suggests that its presence does not lead to complex destabilization.

To examine stable binding and protection of siRNA in the lipoplexes under conditions that can mimic those in vivo, further measurements were performed after incubating both plain and Tf-lipoplexes in the presence of RNase V1 $(0.1 \mathrm{U} / \mu \mathrm{l})$ (Figure $2 \mathrm{a}$ ) or mouse serum (Figures $2 \mathrm{~b}$ and 2c). Following a $30 \mathrm{~min}$ or $4 \mathrm{~h}$ incubation period, respectively, the siRNA present in the mixtures was recovered and analyzed in a polyacrylamide gel stained with ethidium bromide. Both plain and Tflipoplexes significantly protected siRNA from RNase V1 and serum-mediated degradation, whereas naked siRNA was almost completely degraded, in both cases, after a short incubation period (Figures $2 \mathrm{a}$ and $2 \mathrm{~b}$ ). These results clearly indicate that the presence of cationic lipid is crucial to confer protection of siRNA molecules against serum nucleases. The observation that naked siRNA samples remained almost intact upon incubation with heat-inactivated serum suggests that the degradation observed in the presence of serum was of enzymatic origin. Moreover, results from parallel experiments carried out with longer incubation periods in the presence of serum (Figure 2c) indicate that the protection effect mediated

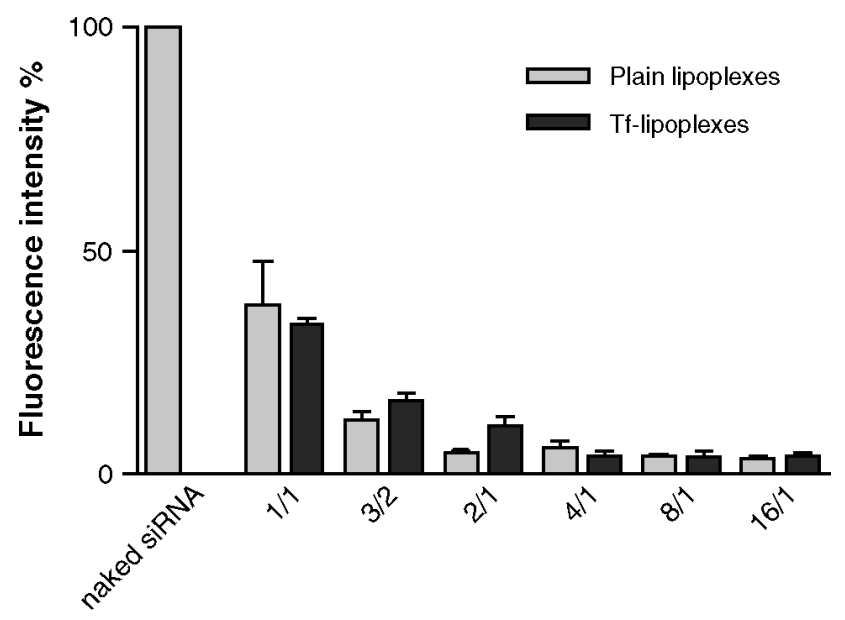

Charge ratio (lipid/siRNA)

Figure 1. siRNA binding in plain or Tf-associated lipoplexes. DOTAP : Chol liposomes were complexed with $400 \mathrm{ng}$ of siRNA in the presence or absence of transferrin (Tf) followed by incubation with the fluorescent probe PicoGreen. Relative fluorescence is presented as percentage of the control obtained with $400 \mathrm{ng}$ naked siRNA. The percentage represents the fraction of siRNA in the sample available for PicoGreen interaction. Results are presented as mean values \pm SD from triplicates and are representative of three independent experiments 
(a)
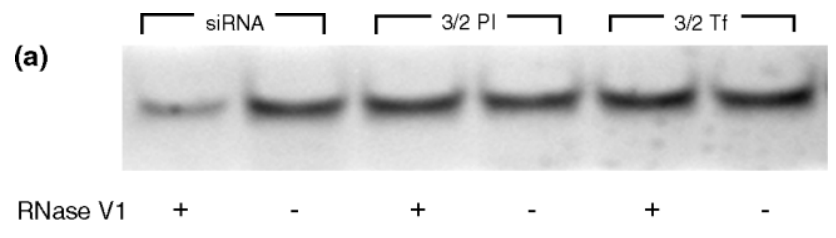

(b)
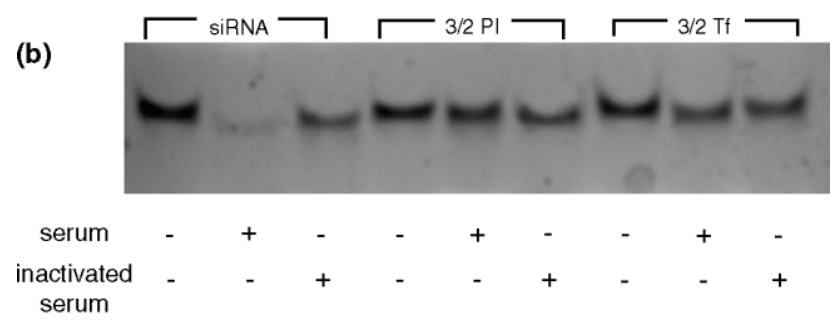

serum $\Gamma 1 \mathrm{~h} \longrightarrow \Gamma 24 \mathrm{~h} \longrightarrow \Gamma 48 \mathrm{~h} \longrightarrow$

(c)

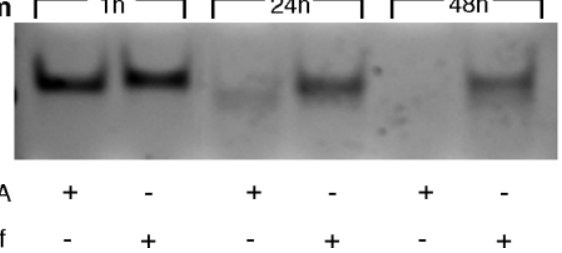

Figure 2. Stability of siRNA in plain or Tf-associated lipoplexes exposed to RNase V1 and mouse serum. Plain lipoplexes or Tf-lipoplexes containing $500 \mathrm{ng}$ siRNA were incubated with RNase V1 or complete mouse serum. After the indicated incubation periods, siRNA was extracted and analyzed by electrophoresis in a $15 \%$ polyacrylamide gel and subsequent staining of the gel with ethidium bromide was performed. Naked siRNA, plain lipoplexes or Tf-lipoplexes prepared at a $3 / 2$ lipid/siRNA charge ratio were incubated for $30 \mathrm{~min}$ in the presence or absence of (a) RNase V1 $(0.1 \mathrm{U} / \mu \mathrm{l})$ or for $4 \mathrm{~h}$ (b) in normal or heat-inactivated mouse serum. (c) In parallel experiments, naked siRNAs and Tf-lipoplexes were incubated for $1 \mathrm{~h}, 24 \mathrm{~h}$ and up to $48 \mathrm{~h}$ in the presence or absence of mouse serum. The results are representative of three independent experiments

by Tf-lipoplexes is still present after $48 \mathrm{~h}$ of exposure to serum, which illustrates the high stability of these complexes over days.

In order to further characterize Tf-lipoplexes, zetapotential and particle size of the two most promising formulations $(3 / 2$ and $2 / 1$ lipid/siRNA $(+/-)$ charge ratios) were evaluated in the presence of serum. Although both formulations presented a negative surface charge, i.e. $-27.5 \pm 3.1 \mathrm{mV}$ and $-7.0 \pm 4.8 \mathrm{mV}$ at charge ratios of $3 / 2$ and $2 / 1$, respectively, Tf-lipoplexes prepared at the $2 / 1$ charge ratio exhibited a zeta-potential value very close to neutrality, which may contribute to the significant difference observed in the size of both formulations. The negatively charged Tf-lipoplexes, prepared at the $3 / 2$ charge ratio, exhibited a size of $328 \pm 64 \mathrm{~nm}$, whereas the nearly neutral particles, prepared at the $2 / 1$ charge ratio, were significantly larger, i.e. $926 \pm 47 \mathrm{~nm}$. This may be attributed to reduced electrostatic repulsions at charge ratios of $2 / 1$ with a consequent increase in particle aggregation compared to the negatively charged $3 / 2$ lipoplexes, which may contribute to differences in siRNA delivery and biological activity.

\section{Cellular uptake of fluorescently labeled siRNAs}

The internalization of Tf-lipoplexes was monitored in Huh-7 cells by confocal microscopy, using Cy3-labeled non-silencing siRNA. The results presented in Figure 3 reveal that $4 \mathrm{~h}$ after the delivery of Cy3-labeled Tfcomplexes, prepared at 2/1 and 4/1 lipid/siRNA charge ratios (Figures $3 \mathrm{a}$ and $3 \mathrm{~b}$, respectively), fluorescent particles were found to be located within very large intracellular vesicles. In contrast, the delivery of a similar amount of naked Cy3-labeled siRNAs (Figure 3c) did not allow detection of red fluorescence within the cells or even in the extracellular medium, suggesting that siRNA degradation or removal upon washing occurs during the incubation period with the cells.

\section{Gene silencing efficiency}

It has been demonstrated that $\mathrm{Tf}$ is highly effective in promoting lipoplex-mediated transfection in various cell lines and primary cell cultures $[30,32,38,43]$. Therefore, we evaluated whether this strategy would also result in an enhancement of siRNA transfer efficiency. Figure 4 illustrates the percentage of GFP-expressing U-373 cells,
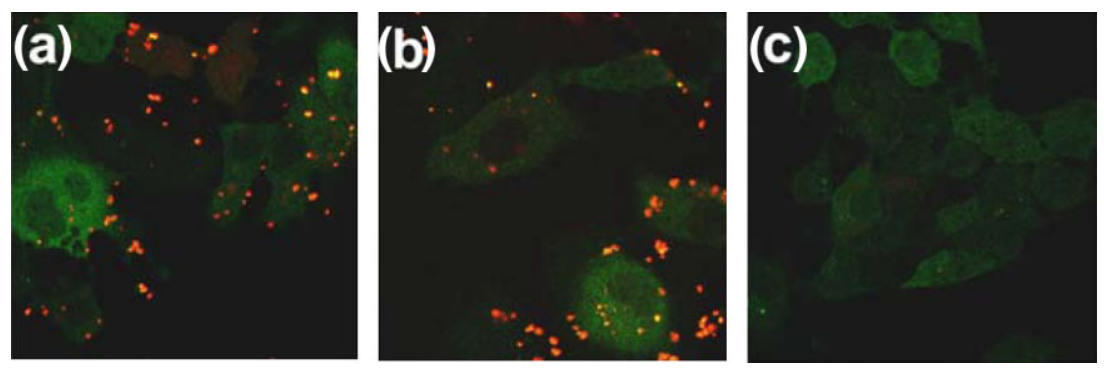

Figure 3. Uptake of naked or Tf-lipoplex associated Cy3-siRNAs in Huh-7 cells. Huh-7 cells were plated 1 day before siRNA delivery and rinsed with DMEM supplemented with 10\% FBS immediately before delivery of Tf-lipoplexes. DOTAP:Chol liposomes were pre-incubated in the presence of Tf (32 $\mu \mathrm{g} / \mu \mathrm{g}$ siRNA), complexed with 50 pmol of Cy3-labeled non-silencing siRNA at 2/1 or 4/1 lipid/siRNA (+/-) charge ratios, and added to the cells for $4 \mathrm{~h}$. In parallel experiments, cells were incubated with the same amount of siRNAs in the absence of liposomes for the same period. After $4 \mathrm{~h}$, the cells were rinsed twice with PBS and immediately observed by confocal microscopy. The panels show representative images at $600 \times$ magnification of cells treated with (a) $2 / 1$ lipid/siRNA Tf-lipolexes, (b) 4/1 lipid/siRNA Tf-lipolexes, and (c) naked Cy3-siRNA. Results are representative of two independent experiments 


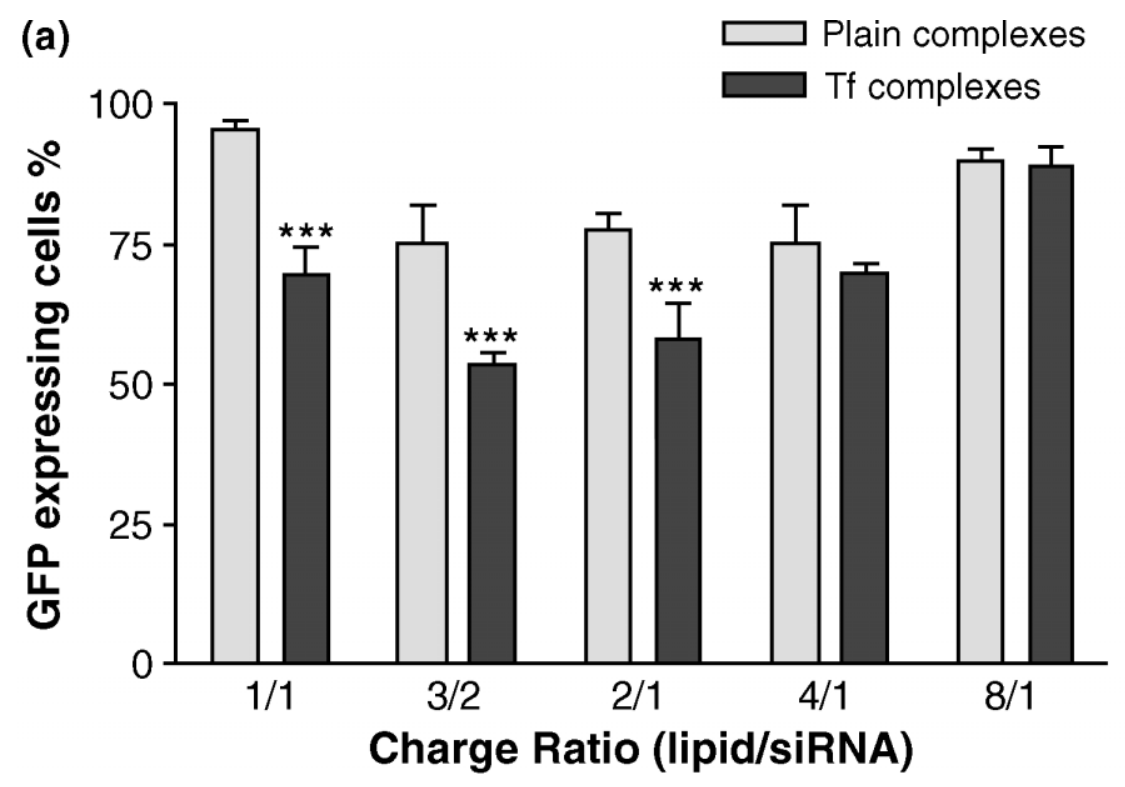

(b)

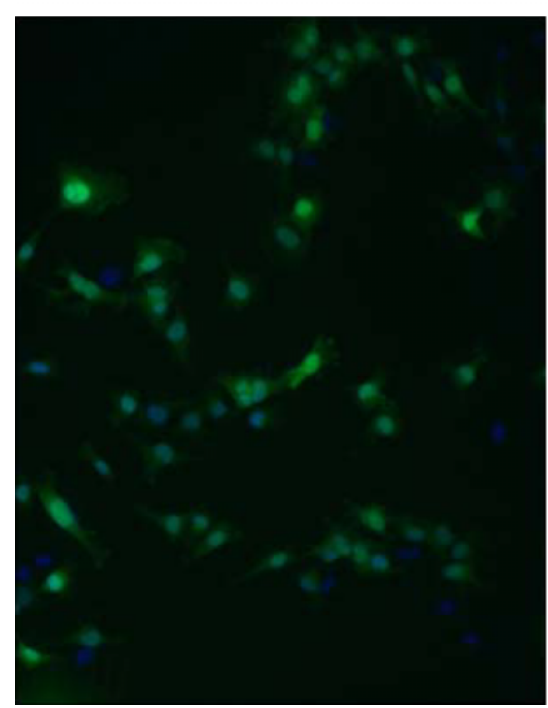

(c)

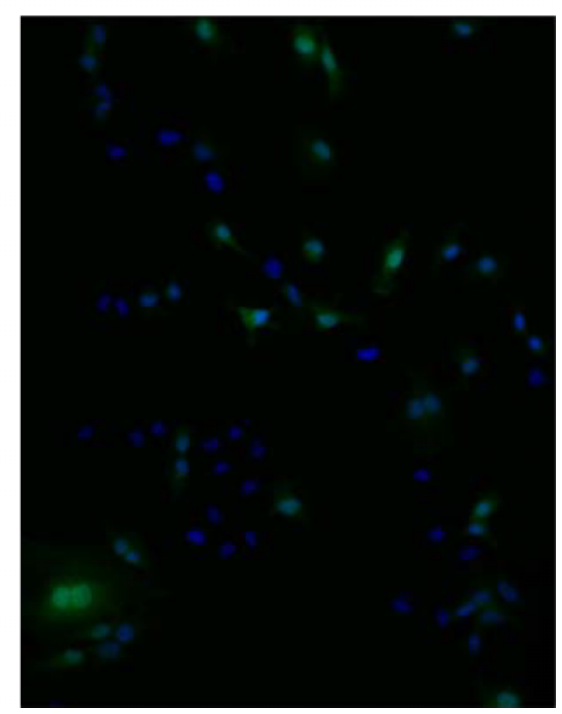

Figure 4. Effect of transferrin association to DOTAP : Chol liposomes on gene silencing in U-373 cells. U-373 cells stably expressing GFP were plated 1 day before siRNA delivery and rinsed with DMEM containing $10 \%$ FBS immediately before complex delivery. DOTAP : Chol liposomes pre-incubated in the presence or absence of Tf ( $32 \mu \mathrm{g} / \mu \mathrm{g}$ siRNA) were complexed with 50 pmol of anti-GFP siRNA at the indicated lipid/siRNA charge ratios and added to the cells to a final siRNA concentration of $100 \mathrm{nM}$. After $4 \mathrm{~h}$ incubation, the medium was replaced with fresh medium and the cells were incubated for a further $48 \mathrm{~h}$ before evaluation of GFP knockdown by epifluorescence microscopy. (a) The number of GFP-expressing cells is presented as percentage of untreated controls. The data are given as mean values $\pm S D$ of triplicates and are representative of three independent experiments. ${ }^{* * *} p<0.001$ compared to plain lipoplexes. Representative images of (b) control cells $(200 x)$ or (c) cells treated with Tf-lipoplexes prepared at 3/2 lipid/siRNA charge ratio $(200 x)$

$48 \mathrm{~h}$ after delivery of plain or Tf-lipoplexes prepared at different lipid/siRNA charge ratios. Association of Tf to the lipoplexes resulted in a significant enhancement of GFP knockdown at low lipid/siRNA $(+/-)$ charge ratios, the best results being observed with Tf-lipoplexes prepared at a charge ratio of $3 / 2$.

In order to establish the average levels of protein knockdown mediated by Tf-lipoplexes at single cell level, GFP silencing in U-373 cells was also evaluated using FACS analysis (Figure 5). Tf-lipoplexes, prepared at different charge ratios and containing anti-GFP siRNA or a non-silencing sequence (Mut siRNA), were incubated with the cells and, $72 \mathrm{~h}$ following delivery, the mean intensity of GFP fluorescence was analyzed for each condition. The values corresponding to the percentage of GFP mean fluorescence were compared to those obtained using the standard commercial lipid-based reagent, Lipofectamine 2000, which is frequently employed for in vitro DNA plasmid transfection and siRNA delivery. As illustrated in Figure 5, approximately 45\% decrease in GFP levels was observed following siRNA delivery using Tf-lipoplexes prepared at a charge ratio of $3 / 2$, a result very similar to 


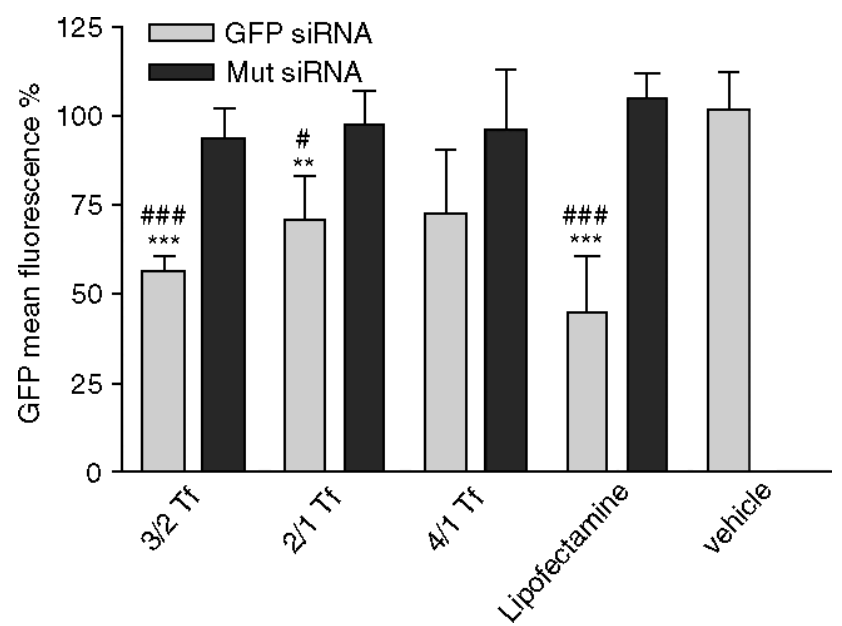

Figure 5. Effect of lipid/siRNA charge ratio of Tf-lipoplexes on gene silencing in U-373 cells. U-373 cells stably expressing GFP were plated 1 day before siRNA delivery and rinsed with DMEM containing $10 \%$ FBS immediately before delivery of the complexes. DOTAP : Chol liposomes were pre-incubated in the presence of Tf $(32 \mu \mathrm{g} / \mu \mathrm{g}$ siRNA) and then complexed with 50 pmol of anti-GFP or non-silencing (Mut) siRNA, at the indicated lipid/siRNA charge ratios, and added to the cells to a final siRNA concentration of $100 \mathrm{nM}$. After $4 \mathrm{~h}$ incubation, the medium was replaced and the cells were incubated for a further $72 \mathrm{~h}$. In parallel experiments, cells were incubated with the same amount of siRNA complexed with Lipofectamine 2000 or with DOTAP : Chol liposomes associated to Tf in the absence of siRNA (vehicle). The results were obtained by flow cytometry $72 \mathrm{~h}$ after siRNA delivery. Mean GFP fluorescence levels in a population of 10000 events/condition are expressed as percentage of untreated controls (mean \pm SD obtained from triplicates) and are representative of three independent experiments. ${ }^{* *} p<0.01,{ }^{* * *} p<0.001$ compared to controls, and ${ }^{\#} p<0.05,{ }^{\# \# \#} p<0.001$ compared to cells treated with Mut siRNA at the same lipid/siRNA charge ratio

the one obtained with Lipofectamine 2000. In contrast, DOTAP : Chol liposomes associated with Tf (vehicle) or Tflipoplexes containing non-functional siRNA (Mut siRNA) did not decrease GFP fluorescence levels, ruling out nonspecific effects due to the vector per se or to the siRNA at the tested concentration.

The efficiency of siRNA-mediated gene silencing was confirmed by Western blot analysis employing both antiGFP siRNA (Figure 6a) and Mut siRNA (Figure 6b). As shown in Figure 6c, among the different lipid/siRNA charge ratios tested, the most pronounced gene silencing (a mean decrease of 50\% in GFP levels) was achieved after delivery of anti-GFP siRNA mediated by Tf-lipoplexes prepared at a $3 / 2$ charge ratio, demonstrating that this is indeed the optimal charge ratio for DOTAP:Chol Tflipoplexes in U-373 cells. Gene silencing was found to be specific, since no GFP knockdown was observed with Mut siRNA (Figure 6d) and the levels of $\alpha$-tubulin were constant for all tested formulations.

In order to evaluate whether the gene silencing effect observed after siRNA delivery mediated by Tf-lipoplexes was not restricted to U-373 cells, parallel transfection experiments were performed in hepatocarcinoma cells (Huh-7), stably transformed to express a luciferase-GFP (a)

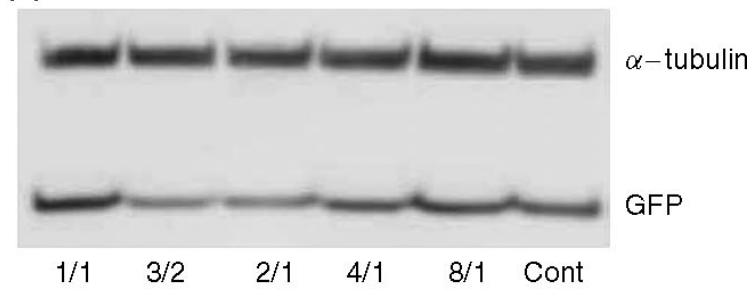

(b)
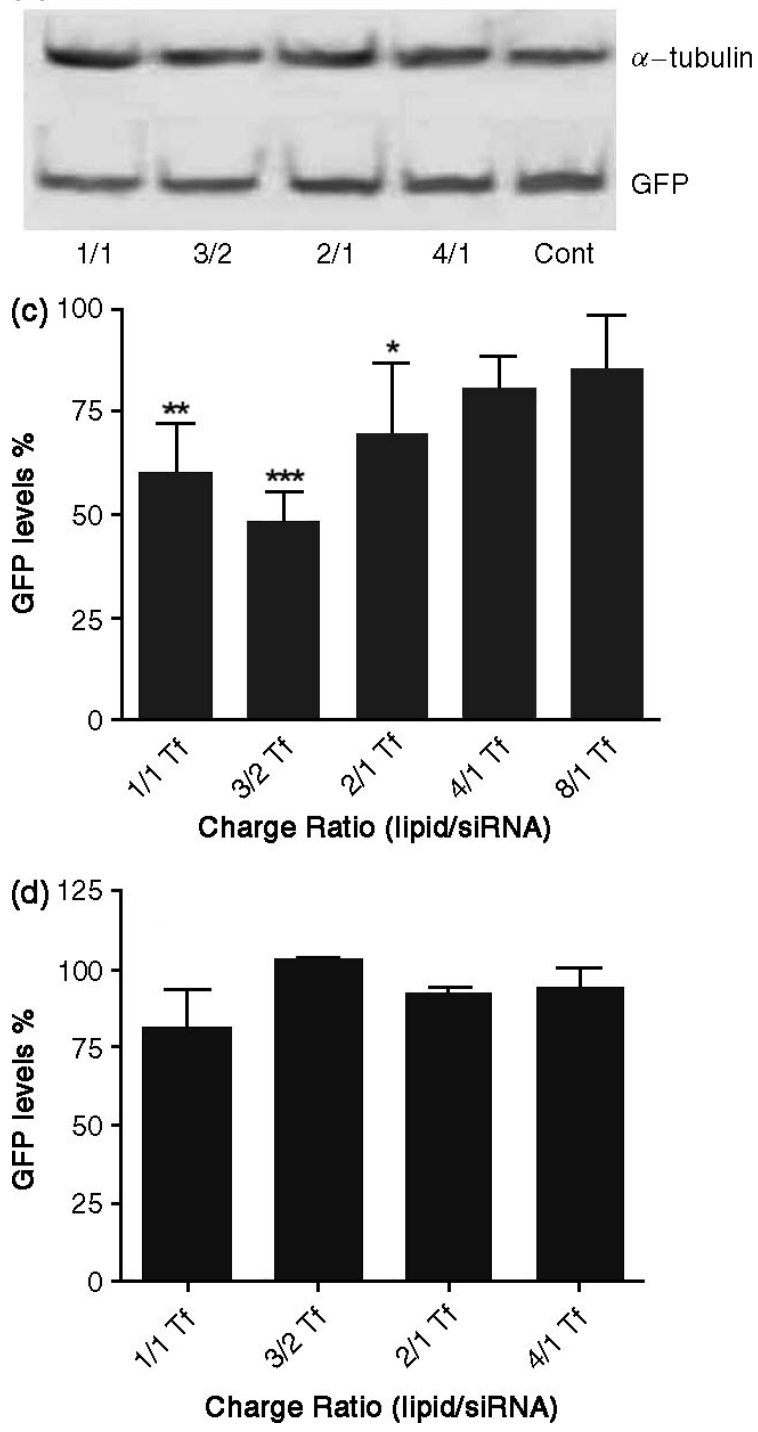

Figure 6. Western blot quantification of Tf-lipoplex-mediated GFP knockdown in U-373 cells. U-373 cells were plated 1 day before siRNA delivery and rinsed with DMEM supplemented with 10\% FBS immediately before complex delivery. DOTAP : Chol liposomes were pre-incubated in the presence of $\mathrm{Tf}(32 \mu \mathrm{g} / \mu \mathrm{g}$ siRNA), complexed with 50 pmol siRNA at the indicated lipid/siRNA charge ratios, and added to the cells to a final siRNA concentration of $100 \mathrm{nM}$. After $4 \mathrm{~h}$ incubation, the medium was replaced with fresh DMEM containing 10\% FBS. After a further $48 \mathrm{~h}$, GFP and $\alpha$-tubulin levels were quantified after immunoblotting of protein extracts obtained from U-373 cells treated with Tf-lipoplexes containing (a) anti-GFP or (b) non-silencing siRNAs. (c, d) Quantification of GFP silencing observed in (a) and (b), respectively, corrected for individual $\alpha$-tubulin signal intensity. Results are expressed as percentage of GFP expression levels in untreated controls. ${ }^{*} p<0.05$, ${ }^{* *} p<0.01$ and ${ }^{* * *} p<0.001$ compared to control 
fusion protein. To assess the silencing efficiency mediated by Tf-lipoplexes, the levels of luciferase gene expression were measured $48 \mathrm{~h}$ after delivery of Mut siRNA or anti-luciferase siRNA (Luc siRNA), and transfection experiments with Lipofectamine 2000 were performed for comparison. As shown in Figure 7, the results are consistent with those obtained in U-373 cells, with the major difference that the levels of luciferase silencing in Huh-7 cells are even higher than those observed for GFP in U-373 cells (cf. Figures 5 and 7). Moreover, the most efficient gene silencing, taking into account the extent and specificity of action, was not observed at a 3/2 lipid/siRNA charge ratio (data not shown) but rather at a 4/1 lipid/siRNA charge ratio, which may be partially attributed to differences in the metabolic activity of U-373 and Huh-7 cells, and thus in their endocytotic capacity. It should be noted that some non-specific silencing of luciferase was observed for lipid/siRNA charge ratios higher than $4 / 1$, as shown by the decrease in the percentage of luciferase activity obtained when employing Mut siRNA. Similar results were observed for gene silencing mediated by Lipofectamine 2000, although to a lower extent.

Overall, these results demonstrate that optimization of lipid/siRNA charge ratios resulted in efficient and specific gene silencing by Tf-associated siRNA/liposome complexes.

\section{Cytotoxicity induced by Tf-lipoplexes}

To evaluate whether Tf-lipoplexes were toxic to cells, cell viability was assessed by the Alamar blue assay, 24 and $48 \mathrm{~h}$ after delivery of the complexes. As shown in Figure 8a, no significant toxicity was observed in U-373 cells, independently of the lipid/siRNA charge ratio. Similar results were observed in Huh-7 cells for the most efficient charge ratios (2/1 and 4/1 lipid/siRNA (+/-)) (data not shown), although some toxicity (25\%) was observed at high charge ratios (6/1 and 8/1 lipid/siRNA $(+/-))$ which correlates with the non-specific effect observed for these formulations (Figure 7). Membrane integrity was evaluated in U-373 cells, using the LDH assay. The results illustrated in Figure $8 \mathrm{~b}$ show that Tflipoplexes are overall well tolerated by the cells, even when prepared at high lipid/siRNA charge ratios.

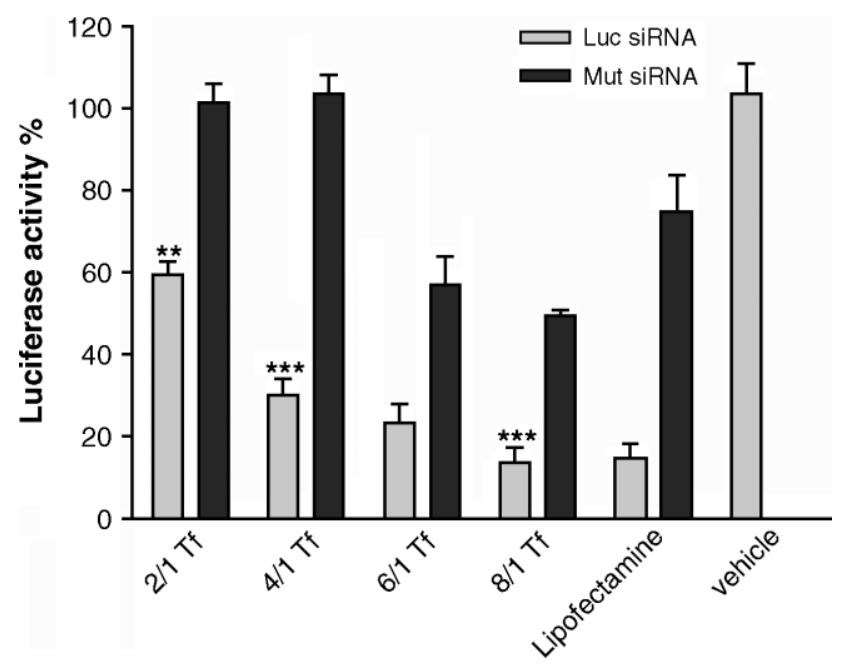

Figure 7. Effect of lipid/siRNA charge ratio of Tf-lipoplexes on luciferase silencing in Huh-7 cells. Huh-7 cells were plated 1 day before siRNA delivery and rinsed with DMEM supplemented with $10 \%$ FBS immediately before delivery of the complexes. DOTAP : Chol liposomes were pre-incubated in the presence of Tf (32 $\mu \mathrm{g} / \mu \mathrm{g}$ siRNA), complexed with $50 \mathrm{pmol}$ of anti-Luciferase or non-silencing (Mut) siRNA at the indicated lipid/siRNA charge ratios, and then added to the cells to a final siRNA concentration of $100 \mathrm{nM}$. After $4 \mathrm{~h}$ incubation, the medium was replaced and the cells were incubated for a further $48 \mathrm{~h}$. Afterwards, relative light units (RLU) were measured in each sample and luciferase activity calculated as percentage of activity in untreated control cells. Mean RLU \pm SD values were obtained from triplicates and are representative of three independent experiments. ${ }^{* *} p<0.01$ and ${ }^{* * *} p<0.001$ compared to cells treated with Mut siRNA

\section{c-Jun silencing and HT-22 protection mediated by Tf-lipoplexes}

In order to demonstrate that Tf-lipoplexes are also able to promote efficient gene silencing of endogenous genes, an endogenous protein was chosen as target (c-Jun) and a complementary siRNA was synthesized based on the mouse c-Jun mRNA sequence. To establish the average decrease in c-Jun mRNA levels, HT-22 immortalized mouse hippocampal neurons were incubated with Tflipoplexes prepared at the 3/2 lipid/siRNA charge ratio and containing anti-c-Jun or non-functional Mut siRNAs. Forty-eight hours after Tf-lipoplex delivery, cJun silencing was evaluated using QRT-PCR (Table 1). The percentage of c-Jun knockdown in this cell line was calculated using the $\Delta \Delta \mathrm{C}_{\mathrm{t}}$ method, as described in the

Table 1. QRT-PCR quantification of Tf-lipoplex-mediated C-Jun knockdown in HT-22 cells ${ }^{\mathrm{a}}$

\begin{tabular}{|c|c|c|c|c|c|c|}
\hline HT-22 cells & $\mathrm{C}_{\mathrm{t}}$ C-Jun & $C_{t}$ HPRT & $\Delta C_{t}$ & $\Delta \Delta C_{t}$ & C-Jun knockdown (\%) & Average C-Jun knockdown (\%) \\
\hline Transfected with anti - C-Jun siRNA & $\begin{array}{l}29.6 \\
29.7 \\
27.6\end{array}$ & $\begin{array}{l}23.5 \\
24.4 \\
23.6\end{array}$ & $\begin{array}{l}6.1 \\
4.9 \\
4.0\end{array}$ & $\begin{array}{l}1.0 \\
1.1 \\
1.0\end{array}$ & $\begin{array}{l}50 \\
53 \\
50\end{array}$ & 51 \\
\hline Transfected with Mut siRNA & $\begin{array}{l}28.7 \\
28.6 \\
26.6\end{array}$ & $\begin{array}{l}23.6 \\
24.8 \\
23.6\end{array}$ & $\begin{array}{l}5.1 \\
3.8 \\
3.0\end{array}$ & & & \\
\hline
\end{tabular}

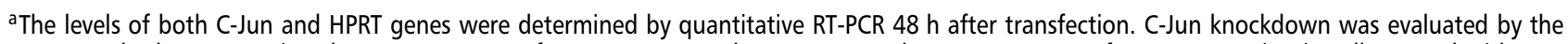
$\Delta \Delta C_{t}$ method $(n=3)$ using the HPRT gene as reference gene. Results are expressed as a percentage of C-Jun expression in cells treated with Mut siRNAs. 

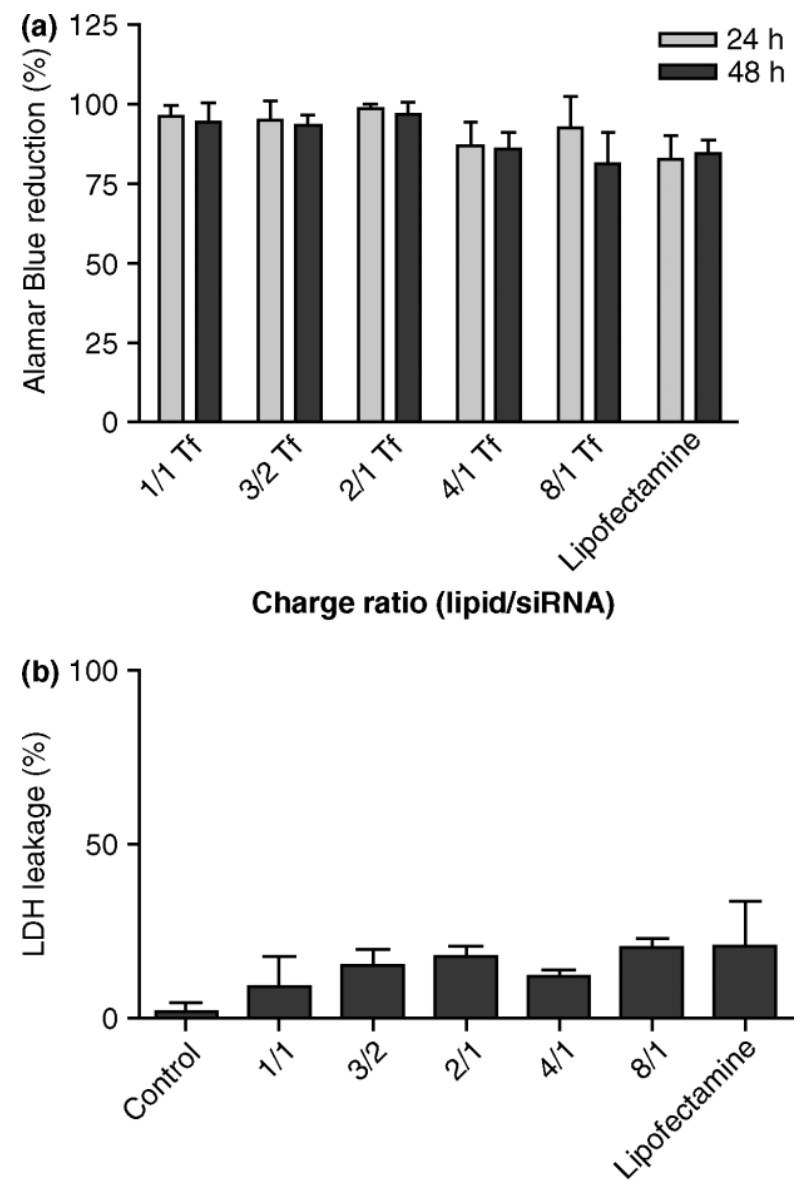

Charge ratio (lipid/siRNA)

Figure 8. Effect of Tf-lipoplexes on the viability and membrane integrity of U-373 cells. U-373 cells were plated 1 day before siRNA delivery and rinsed with DMEM supplemented with $10 \%$ FBS immediately before delivery of Tf-lipoplexes. DOTAP : Chol liposomes were pre-incubated in the presence of $\mathrm{Tf}(32 \mu \mathrm{g} / \mu \mathrm{g}$ siRNA), complexed with 50 pmol of non-silencing (Mut) siRNA at the indicated lipid/siRNA charge ratios, and added to the cells to a final siRNA concentration of $100 \mathrm{nM}$. After $4 \mathrm{~h}$ incubation, the medium was replaced with fresh DMEM with $10 \%$ FBS and the cells were incubated for a further 24 or $48 \mathrm{~h}$. (a) Cell viability was determined by the Alamar blue assay. The data are expressed as percentage of untreated controls. (b) Membrane integrity was evaluated employing the LDH assay. Results are expressed as the percentage of total LDH (intracellular LDH + extracellular LDH). Mean values for LDH activity in the medium \pm SD were obtained from triplicates and are representative of three independent experiments. No significant statistical differences were observed

Materials and methods section. In this experiment, the mean $\Delta \Delta \mathrm{C}_{\mathrm{t}}$ value found was 1.0 , which translates into $51 \%$ of c-Jun knockdown. Moreover, two endogenous reference genes, whose expression should not differ between samples, were used in this study as normalization controls. The expression levels of both the glyceraldehyde3-phosphate dehydrogenase (GAPDH) and Hypoxanthineguanine phosphoribosyltransferase (HPRT) genes did not differ between control (non-transfected) cells and cells treated with Tf-complexes, which indicates that no nonspecific mRNA downregulation occurs due to the vector perse.
C-Jun is a transcription factor that promotes cell death through transactivation of pro-apoptotic factors after glutamate-induced damage in neurons. Therefore, we also investigated whether the observed c-Jun knockdown mediated by Tf-lipolexes was sufficient to attenuate cell death after glutamate exposure in HT-22 cells. The results presented in Figure 9 show that HT-22 neurons pre-treated with anti-c-Jun siRNA show 40\% increase in viability after glutamate exposure compared to nontransfected cells or cells pre-treated with non-functional Mut siRNA. The protective effect by c-Jun siRNA was apparently specific, since Mut siRNA did not affect glutamate toxicity. Altogether, the results from QRT-PCR (Table 1) and the MTT assay (Figure 9) clearly show that the achieved c-Jun knockdown is capable of inducing a significant therapeutic effect in HT-22 cells, protecting them from glutamate-mediated cell death.

\section{Discussion}

The recently discovered RNAi pathway is based on the cytoplasmic degradation of target mRNA by small double-stranded RNA molecules complementary to the mRNA sequence. siRNA molecules constitute already a

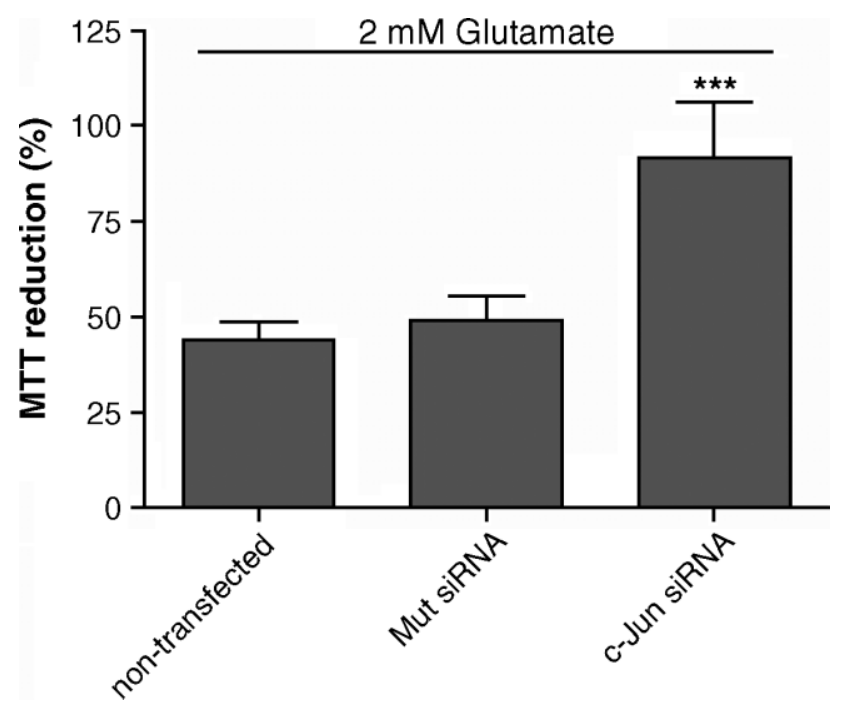

Figure 9. Effect of c-Jun silencing mediated by Tf-complexes on the viability of HT-22 cells after glutamate damage. HT-22 cells were plated 1 day before siRNA delivery and rinsed with DMEM supplemented with $10 \%$ FBS immediately before delivery of Tf-lipoplexes. DOTAP : Chol liposomes were complexed, in the presence of Tf (32 $\mu \mathrm{g} / \mu \mathrm{g}$ siRNA), with $25 \mathrm{pmol}$ of anti-c-Jun siRNA (c-Jun siRNA) or non-silencing siRNA (Mut siRNA) at the $3 / 2 \mathrm{lipid} /$ siRNA charge ratio, and added to the cells to a final siRNA concentration of $50 \mathrm{nM}$. After $4 \mathrm{~h}$ incubation, the medium was replaced with fresh DMEM with $10 \%$ FBS and the cells were incubated for a further $48 \mathrm{~h}$. After this period transfected and non-transfected cells were treated with $2 \mathrm{mM}$ glutamate and incubated for $18 \mathrm{~h}$ before cell viability evaluation by the MTT assay. The data are expressed as percentage of non-transfected and untreated controls. Mean $\mathrm{RLU} \pm \mathrm{SD}$ were obtained from triplicates and are representative of three independent experiments. ${ }^{* * *} p<0.001$ compared to cells treated with Mut siRNA 
popular tool in the fields of functional genomics [4,50,51] and target validation, and have recently started to be studied as a new strategy to control gene expression in disease models. As opposed to plasmid DNA delivery, this process does not present the delivery hurdle of nuclear entry which significantly hampers most of the conventional gene therapy approaches. Also, the process of RNA interference does not involve modifications of the cellular genome and employs highly specific and efficient endogenous enzymatic machinery which is ubiquitously distributed in the mammalian organism. Nevertheless, the successful application of the RNAi approach both in vitro and in vivo, especially in therapeutic approaches, depends on the development of delivery systems capable of reaching the target cells, in a stable, non-toxic and efficient way. Tf-associated cationic liposomes have been successfully employed for plasmid DNA delivery not only in cancer cells, but also in normal cells, such as neurons, both in cell culture and in animal models $[29,30]$, where they mediated a significant enhancement in transfection efficiency as compared to conventional lipoplexes. Motivated by these results, we decided to examine the potential of Tf-associated lipoplexes for siRNA delivery.

While exhibiting some similarity, DNA and siRNA present several important differences that may prove crucial in terms of complex formation upon their interaction with cationic lipids. Due to their small size, synthetic siRNA molecules do not necessarily require the same process of condensation that leads to the collapse of plasmid DNA into nanostructures, in the presence of a cationic agent. Instead, siRNA molecules may retain their initial structure after interaction with the positively charged lipid headgroups and, therefore, it is not possible to predict siRNA/lipid interactions based on the previous knowledge of plasmid DNA behavior. The siRNA-specific properties may lead to the formation of particles that do not allow complete nucleic acid condensation, which in turn can result in degradation by macromolecules present in the extracellular environment and thereby in low gene silencing levels. For this reason, we initiated our study by assessing several parameters, such as the extent of lipid/siRNA association and the siRNA protection efficiency conferred by the cationic lipid, which helped predict the biological stability of the complexes. Results from these experiments revealed that even at low lipid/siRNA charge ratio $(3 / 2)$, siRNA associated extensively with cationic liposomes both in the absence and presence of transferrin (Figure 1), resulting in stable complexes capable of conferring significant protection to the carried molecules (Figure 2), thereby inhibiting serum-mediated siRNA degradation even after long incubation periods (Figure 2c). The stability of lipid-based vectors in serum is especially important since the inhibitory effect of serum on transfection has been one of the major drawbacks when trying to transpose these systems from cell culture conditions to animal models, aiming at therapeutic applications. Serum increases the size of cationic liposomes by inducing aggregation due to interaction of negatively charged proteins with the lipid headgroups. Although DOPE is usually the first choice as helper lipid for in vitro experiments, complexes containing cholesterol have been shown to be more active in vivo, which may be attributed to their high stability in biological fluids, as a consequence of a lower interaction with serum proteins.

Results from confocal microscopy on the intracellular uptake of Tf-lipoplexes demonstrated that for both tested charge ratios ( $3 / 2$ and $2 / 1$ lipid/siRNA), the lipoplexes were localized inside Huh-7 cells $4 \mathrm{~h}$ after delivery (Figure 3). In contrast, after incubation with naked Cy3labeled siRNA, no fluorescence was observed inside or outside the cells, which may be due to siRNA degradation by serum enzymes present in the culture medium. These results reinforce the need to employ vectors capable of protecting the siRNA molecules following their administration.

In order to evaluate the biological activity of siRNA complexes with DOTAP: Chol liposomes we performed a series of studies focused on the major feature of the siRNA pathway, namely the ability to induce gene silencing and protein knockdown. Our results (Figures 4-7) clearly demonstrate that association of siRNAs to Tf-containing cationic liposomes resulted in a significant enhancement of gene silencing. This correlates to the observed decrease in the levels of reporter proteins, thus suggesting that an efficient knockdown of therapeutic-relevant targets may be achieved when employing this kind of vector. Consistent with results from our previous studies on plasmid DNA, coating of cationic liposomes with Tf enhances gene silencing by siRNA as compared to plain complexes (Figure 4), which is probably due to promotion of cellular uptake of the Tf-lipoplexes through the endocytotic pathway and cytoplasmic delivery of the carried siRNA molecules by destabilization of the endosomal membrane under acidic conditions [32].

Our observations that the optimal siRNA/lipid charge ratio albeit always positive varied considerably between the tested cell lines suggest that there is an ideal charge ratio for efficient gene silencing, depending on the cell type. As illustrated in Figures 5 and 7, a specific downregulation upon delivery of Tf-lipoplexes was demonstrated, which is of crucial importance for our work to be of value for future clinical applications $[1,52]$.

Recently, several studies have suggested that activation of the mammalian immune system by siRNAs is dosedependent [25], caused by nucleoside modifications $[27,53]$, or stimulated by certain nucleotide sequences frequently found in viral RNA [54]. Careful analysis revealed that the siRNAs employed in our study do not contain any of the known sequences that may cause such immune responses. Moreover, we tested the lipid vehicle alone (liposomes associated to $\mathrm{Tf}$ ), taking into consideration reports concerning a possible role of lipidbased vectors in non-specific silencing effects $[28,55,56]$. 
As shown in Figure 5, no GFP reduction was observed for this condition. However, at high lipid/siRNA charge ratios a significant luciferase silencing was observed for the Mut siRNA in Huh-7 cells (Figure 7) suggesting that the lipid, when present at high concentrations and associated with siRNAs, can indeed contribute to a nonspecific protein decrease [56]. This may stimulate the activation of Toll-like receptors 7 and $8[26,27,53,57]$ and the respective downstream pathways, which lead to expression of IFN and pro-inflammatory cytokines. This effect was also observed with Lipofectamine 2000, which reinforces the need to always employ the lowest effective dose of the nucleic acid delivery agent, as well as a non-silencing control, even when siRNA delivery is mediated by a commercial reagent [23]. Nevertheless, this was not verified in the U-373 cells, which indicates that these non-specific effects may be cell-type-specific, as has been recently suggested [58].

The toxicity assays revealed that $\mathrm{Tf}$-lipoplexes were slightly better tolerated by the cells than Lipofectamine 2000 and, notably, the toxicity of lipoplexes prepared at low lipid/siRNA charge ratios was even negligible. This low toxicity level was observed not only for cell lines, but also for primary neuronal cultures (data not shown). Moreover, recent experiments involving siRNA delivery into neuronal cultures and after local injection into the mouse brain have clearly shown that Tf-lipoplexes are able to mediate high levels of gene silencing in this type of non-dividing cells in vitro and in vivo (Cardoso et al., manuscript in preparation). These results are promising considering the potential applications of Tf-lipoplexes in experimental models of neurodegenerative disorders, where high toxic effects and low gene silencing efficiency are major drawbacks when employing available standard transfection reagents.

In order to clarify the potential of Tf-lipoplexes to mediate gene silencing of both reporter and endogenous genes, and as a first approach to a possible therapeutic application of these lipid-based vectors, we selected the c-Jun gene as target gene and investigated c-Jun knockdown in a glutamate-sensitive cell-line. The QRT-PCR results presented in Table 1 show a significant downregulation of c-Jun mRNA (51\%) after delivery of Tf-complexes without detectable off-target effects.

Due to its important role as a transcription factor in several well-described pathways of apoptotic cell death in neurons, c-Jun is a promising target for therapeutic applications in neurodegenerative conditions, including glutamate-induced cell death [46]. Here, we demonstrate that c-Jun targeting siRNA mediates a pronounced decrease in c-Jun mRNA levels and significantly protects neuronal cells (Figure 9) from glutamate-induced damage, which confirms the potential of Tf-complexes to mediate an efficient therapeutic effect. The protective effect obtained with c-Jun siRNA in the present model system of glutamate-mediated neurotoxicity in vitro is well in line with protective effects against excitotoxic neuronal death observed in mice expressing an inactive form of c-Jun [59]. It is important to note that, although c-Jun silencing in HT-22 cells was approximately 50\%, the protective effect observed in this cell line was highly significant, indicating that for this target a complete knockdown is not necessary to obtain a relevant therapeutic effect.

Taken together, this study demonstrates that, similarly to what has been previously shown for plasmid DNA, DOTAP : Cholestrol liposomes associated to transferrin can mediate efficient intracellular siRNA delivery. Our findings clearly show that Tf-associated lipoplexes, when prepared at the adequate charge ratios, promote protein silencing in vitro which, together with previous results concerning their in vivo application [29], suggests that they may be a promising strategy to translate laboratory research to clinical application.

\section{Acknowledgements}

A.L.C. Cardoso is the recipient of a fellowship from the Portuguese Foundation for Science and Technology (SFRH/BD/17216/2004). This work was partially financed by a grant from the Portuguese Foundation for Science and Technology (POCTI/CVT/44854/2002). C. Culmsee is supported by the Alzheimer Forschungs Initiative.

\section{References}

1. Caplen NJ. Gene therapy progress and prospects. Downregulating gene expression: the impact of RNA interference. Gene Ther 2004; 11: 1241-1248.

2. Fire A, et al. Potent and specific genetic interference by doublestranded RNA in Caenorhabditis elegans. Nature 1998; 391: 806-811.

3. Napoli C, Lemieux C, Jorgensen R. Introduction of a chimeric chalcone synthase gene into petunia results in reversible cosuppression of homologous genes in trans. Plant Cell 1990; 2: 279-289.

4. Hannon GJ, Rossi JJ. Unlocking the potential of the human genome with RNA interference. Nature 2004; 431: 371-378.

5. Gitlin L, Karelsky S, Andino R. Short interfering RNA confers intracellular antiviral immunity in human cells. Nature 2002; 418: $430-434$.

6. Jacque JM, Triques K, Stevenson M. Modulation of HIV-1 replication by RNA interference. Nature 2002; 418: 435-438.

7. Lee NS, et al. Expression of small interfering RNAs targeted against HIV-1 rev transcripts in human cells. Nat Biotechnol 2002; 20: 500-505.

8. Brummelkamp TR, Bernards R, Agami R. Stable suppression of tumorigenicity by virus-mediated RNA interference. Cancer Cell 2002; 2: 243-247.

9. Scherr $\mathrm{M}$, et al. Specific inhibition of bcr-abl gene expression by small interfering RNA. Blood 2003; 101: 1566-1569.

10. Wilda M, Fuchs U, Wossmann W, Borkhardt A. Killing of leukemic cells with a BCR/ABL fusion gene by RNA interference (RNAi). Oncogene 2002; 21: 5716-5724.

11. Wohlbold L, et al. Inhibition of bcr-abl gene expression by small interfering RNA sensitizes for imatinib mesylate (STI571). Blood 2003; 102: 2236-2239.

12. Song E, et al. RNA interference targeting Fas protects mice from fulminant hepatitis. Nat Med 2003; 9: 347-351. 
13. Zender L, et al. Caspase 8 small interfering RNA prevents acute liver failure in mice. Proc Natl Acad Sci US A 2003; 100: 7797-7802.

14. Ding $\mathrm{H}$, et al. Selective silencing by RNAi of a dominant allele that causes amyotrophic lateral sclerosis. Aging Cell 2003; 2: 209-217.

15. Gonzalez-Alegre P, Miller VM, Davidson BL, Paulson HL. Toward therapy for DYT1 dystonia: allele-specific silencing of mutant TorsinA. Ann Neurol 2003; 53: 781-787.

16. Miller VM, et al. Allele-specific silencing of dominant disease genes. Proc Natl Acad Sci U S A 2003; 100: 7195-7200.

17. Bernstein E, Caudy AA, Hammond SM, Hannon GJ. Role for a bidentate ribonuclease in the initiation step of RNA interference. Nature 2001; 409: 363-366.

18. Martinez J, et al. Single-stranded antisense siRNAs guide target RNA cleavage in RNAi. Cell 2002; 110: 563-574.

19. Zamore PD, Tuschl T, Sharp PA, Bartel DP. RNAi: doublestranded RNA directs the ATP-dependent cleavage of mRNA at 21 to 23 nucleotide intervals. Cell 2000; 101: 25-33.

20. Brantl S. Antisense-RNA regulation and RNA interference. Biochim Biophys Acta 2002; 1575: 15-25.

21. Calegari F, et al. Tissue-specific RNA interference in postimplantation mouse embryos with endoribonucleaseprepared short interfering RNA. Proc Natl Acad Sci U S A 2002; 99: 14236-14240.

22. Matsuda T, Cepko CL. Electroporation and RNA interference in the rodent retina in vivo and in vitro. Proc Natl Acad Sci U S A 2004; 101: 16-22.

23. Spagnou S, Miller AD, Keller M. Lipidic carriers of siRNA: differences in the formulation, cellular uptake, and delivery with plasmid DNA. Biochemistry 2004; 43: 13348-13356.

24. Behlke MA. Progress towards in vivo use of siRNAs. Mol Ther 2006; 13: 644-670.

25. Frantz S. Safety concerns raised over RNA interference. Nat Rev Drug Discov 2006; 5: 528-529.

26. Marques JT, Williams BR. Activation of the mammalian immune system by siRNAs. Nat Biotechnol 2005; 23: 1399-1405.

27. Sioud M. Innate sensing of self and non-self RNAs by Toll-like receptors. Trends Mol Med 2006; 12: 167-176.

28. Sledz CA, et al. Activation of the interferon system by shortinterfering RNAs. Nat Cell Biol 2003; 5: 834-839.

29. da Cruz MT, et al. Tf-lipoplex-mediated NGF gene transfer to the CNS: neuronal protection and recovery in an excitotoxic model of brain injury. Gene Ther 2005; 12: 1242-1252.

30. da Cruz MT, Simoes S, de Lima MC. Improving lipoplexmediated gene transfer into C6 glioma cells and primary neurons. Exp Neurol 2004; 187: 65-75.

31. Simoes S, et al. Cationic liposomes for gene delivery. Expert Opin Drug Deliv 2005; 2: 237-254.

32. Simoes $\mathrm{S}$, et al. Mechanisms of gene transfer mediated by lipoplexes associated with targeting ligands or $\mathrm{pH}$-sensitive peptides. Gene Ther 1999; 6: 1798-1807.

33. da Cruz MT, et al. Kinetic analysis of the initial steps involved in lipoplex-cell interactions: effect of various factors that influence transfection activity. Biochim Biophys Acta 2001; 1510: $136-151$.

34. Crook K, Stevenson BJ, Dubouchet M, Porteous DJ. Inclusion of cholesterol in DOTAP transfection complexes increases the delivery of DNA to cells in vitro in the presence of serum. Gene Ther 1998; 5: 137-143.

35. Hirsch-Lerner D, et al. Effect of "helper lipid" on lipoplex electrostatics. Biochim Biophys Acta 2005; 1714: 71-84.

36. Simberg D, Weisman S, Talmon Y, Barenholz Y. DOTAP (and other cationic lipids): chemistry, biophysics, and transfection. Crit Rev Ther Drug Carrier Syst 2004; 21: 257-317.

37. Simberg D, Weiss A, Barenholz Y. Reversible mode of binding of serum proteins to DOTAP/cholesterol Lipoplexes: a possible explanation for intravenous lipofection efficiency. Hum Gene Ther 2005; 16: 1087-1096.

38. Simoes S, et al. Transfection of human macrophages by lipoplexes via the combined use of transferrin and $\mathrm{pH}$-sensitive peptides. J Leukoc Biol 1999; 65: 270-279.

39. Li H, Qian ZM. Transferrin/transferrin receptor-mediated drug delivery. Med Res Rev 2002; 22: 225-250.

40. Shi N, Boado RJ, Pardridge WM. Receptor-mediated gene targeting to tissues in vivo following intravenous administration of pegylated immunoliposomes. Pharm Res 2001; 18: 1091-1095.

41. Shi $\mathrm{N}$, et al. Brain-specific expression of an exogenous gene after i.v. administration. Proc Natl Acad Sci U S A 2001; 98: 12754-12759.

42. Hatakeyama $\mathrm{H}$, et al. Factors governing the in vivo tissue uptake of transferrin-coupled polyethylene glycol liposomes in vivo. Int J Pharm 2004; 281: 25-33.

43. Simoes $\mathrm{S}$, et al. Gene delivery by negatively charged ternary complexes of DNA, cationic liposomes and transferrin or fusigenic peptides. Gene Ther 1998; 5: 955-964.

44. Tros de Ilarduya C, Duzgunes N. Efficient gene transfer by transferrin lipoplexes in the presence of serum. Biochim Biophys Acta 2000; 1463: 333-342.

45. Pedroso de Lima MC, et al. Cationic lipid-DNA complexes in gene delivery: from biophysics to biological applications. $A d v$ Drug Deliv Rev 2001; 47: 277-294.

46. Raivich G, Behrens A. Role of the AP-1 transcription factor c-Jun in developing, adult and injured brain. Prog Neurobiol 2006; 78: 347-363.

47. Campbell MJ. Lipofection reagents prepared by a simple ethanol injection technique. Biotechniques 1995; 18: 1027-1032.

48. Tan S, Wood M, Maher P. Oxidative stress induces a form of programmed cell death with characteristics of both apoptosis and necrosis in neuronal cells. J Neurochem 1998; 71: 95-105.

49. Konopka K, Pretzer E, Felgner PL, Duzgunes N. Human immunodeficiency virus type-1 (HIV-1) infection increases the sensitivity of macrophages and THP-1 cells to cytotoxicity by cationic liposomes. Biochim Biophys Acta 1996; 1312: 186-196.

50. Ambros V. The functions of animal microRNAs. Nature 2004; 431: 350-355.

51. Lippman Z, Martienssen R. The role of RNA interference in heterochromatic silencing. Nature 2004; 431: 364-370.

52. Mittal V. Improving the efficiency of RNA interference in mammals. Nat Rev Genet 2004; 5: 355-365.

53. Kariko K, Buckstein M, Ni H, Weissman D. Suppression of RNA recognition by Toll-like receptors: the impact of nucleoside modification and the evolutionary origin of RNA. Immunity 2005; 23: 165-175.

54. Judge AD, et al. Sequence-dependent stimulation of the mammalian innate immune response by synthetic siRNA. Nat Biotechnol 2005; 23: 457-462.

55. Bridge AJ, et al. Induction of an interferon response by RNAi vectors in mammalian cells. Nat Genet 2003; 34: 263-264.

56. Ma Z, et al. Cationic lipids enhance siRNA-mediated interferon response in mice. Biochem Biophys Res Commun 2005; 330: 755-759.

57. Agrawal S, Kandimalla ER. Role of Toll-like receptors in antisense and siRNA [corrected]. Nat Biotechnol 2004; 22: $1533-1537$.

58. Yoo JW, Hong SW, Kim S, Lee DK. Inflammatory cytokine induction by siRNAs is cell type- and transfection reagentspecific. Biochem Biophys Res Commun 2006; 347: 1053-1058.

59. Behrens A, Sibilia M, Wagner EF. Amino-terminal phosphorylation of c-Jun regulates stress-induced apoptosis and cellular proliferation. Nat Genet 1999; 21: 326-329. 